\title{
Effects of overtraining on the establishment of mental set in anagram solving
}

JAMES F. JUOLA AND B. R. HERGENHAHN HAMLINE UNIVERSITY

Three groups of $10 \mathrm{Ss}$ each solved a list of 60 anagrams. In a set group $(S)$ the first 45 anagrams were five-letter words rearranged into a 54123 letter-order pattern. In a random-set group (RS) the first 30 anagrams were in several varying letter arrangements followed by 15 anagrams in the 54123 order. $A$ random group $(R)$ received 45 anagrams in varying letter arrangements. The last 15 anagrams for all three groups were arranged in a 32145 order. The median solution times for the $S$ group were significantly faster than those of the $R S$ group in the last 15 trials.

Rees \& Israel (1935) demonstrated that as Ss learned to use a set method in solving anagrams, their solution times improved significantly. Anagrams were used that had solution words related in meaning (e.g., all nature set: SWAMP, DAISY, PLANT, etc.) or had the same rearrangement order of the letters to form the anagram (e.g., 54123: PLANT becomes TNPLA). Both types of sets were used by Ss to improve solution times, though the letterorder set proved to be the more effective.

In an experiment designed to test the rigidity of mental set, Maltzman \& Morrisett (1953) had Ss solve 20 anagrams that could all be solved by using the same letter-order set (32145), In a following test, these Ss persisted in using the learned set solution method even though each anagram had several possible solution words.

An earlier study (Maltzman \& Morrisett, 1952) tested the effects of habit strength on mental set. Two groups of Ss were used, each with a different training list. A strong-habit group solved 20 anagrams from a random combination of two 10-word lists, with the words in each list related in meaning. A weak-habit group solved 16 anagrams whose solution words were not related in meaning, and then four anagrams, two taken from each of the two lists given to the strong-habit group. In 10 following trials, all Ss solved anagrams with solution words belonging to only one of the two meaning sets used. It was found that the weak-habit group solved the last 10 anagrams faster. The explanation offered was that the strong-habit group tended to become more rigid in responding to two combined sets and had more difflculty in learning a new, single set.

The present study was designed to test the effects of level of training on the use of a set letter-order arrangement in anagram solving. It was hypothesized that rather than causing rigidity of behavior, overtraining would facilitate the adoption of a new mental set, and thus overtrained Ss would solve anagrams in a new order set faster than criterion trained Ss.

\section{Method}

The Ss were 30 students from an introductory psychology course at Hamline University.

The words used were taken from the lists of the 1000 most common words, as given in Thorndike \& Lorge (1944), on the basis of two criteria: (1) none of the five letters were repeated in the word, and (2) the letters could be arranged to make only one word.

Each $S$ received the anagrams in the same sequence, typed in lower case letters down the center of an $8.5 \times 11$ in. plece of paper. Over this paper was placed a piece of cardboard of the same size with a narrow slot cut into one edge to allow $S$ to work on only one anagram at a time.

In the random group (R), five different letter arrangements were used in random order to make the anagrams for the first 45 trials. In the random-set group (RS), the same letter arrangements were used for the first 30 trials as in the $R$ group, and Trials 31-45 consisted of 15 anagrams with a 54123 letterorder pattern. In the set group (S), all 45 anagrams were in the 54123 pattern. Immediately following the training trials on the list were 15 test anagrams which were all in a 32145 pattern and were exactly the same for all three groups.

The following instructions were read to each $S$ :

"In this experiment you will be asked to solve 60 anagrams, each of which is a five-letter word with its letters rearranged in nonsense order. Before you is a sheet of paper with the anagrams typed in a column down the center. When I say 'begin' you are to slide the cardboard down until the first anagram is visible in the slot. When you know what the solution word 1s, tell me the word so that I can record the time. I will then say 'next' and you are to go on to the next anagram. You will have a limit of $60 \mathrm{sec}$ for each anagram. If you do not solve the anagram within the time limit, I will tell you what the word is before you proceed to the next anagram."

Solution times were recorded with a stopwatch. Results

In the first 30 trials the performance curves of the $R$ and RS groups closely approximated each other (median solution times: $R, 4.25 \mathrm{sec}$, RS, $5.0 \mathrm{sec}$ ), while the $\mathbf{S}$ group showed rapid improvement over the first 10 trials and a stable median solution time of $2.0 \mathrm{sec}$ from then on. In Trials 31-45 the RS group quickly learned the set to achieve a median solution time of $2.0 \mathrm{sec}$ in Trials 40-45, as compared with 
Table 1. Median Solution Times, in sec, for 15 Anagrams (Trials 46-60, 32145 pattern)

\begin{tabular}{lrrr} 
Solution word & \multicolumn{3}{c}{$\begin{array}{c}\text { Experimental group } \\
\text { RS }\end{array}$} \\
\hline right & $R$ & 13.0 & $S$ \\
along & 3.0 & 60.0 & 5.0 \\
given & 52.0 & 5.0 & 33.0 \\
story & 7.5 & 6.5 & 3.0 \\
sound & 13.5 & 2.0 & 2.0 \\
month & 2.0 & 2.0 & 1.0 \\
court & 2.0 & 8.5 & 2.5 \\
price & 9.0 & 15.0 & 7.0 \\
light & 23.5 & 10.0 & 3.5 \\
party & 3.0 & 4.5 & 3.0 \\
force & 2.5 & 3.5 & 2.5 \\
black & 3.0 & 3.0 & 1.0 \\
might & 4.5 & 4.0 & 3.0 \\
alone & 3.0 & 4.0 & 3.5 \\
above & 9.0 & 3.0 & 3.5 \\
\hline
\end{tabular}

18.0 sec for the $\mathrm{R}$ group and 2.0 sec for the $\mathrm{S}$ group for the same five anagrams.

All groups showed consistent improvement in performance through the last 15 trials, as shown in Table 1, making it necessary to compare group performances on one anagram at a time. If, under the null hypothesis, it can be assumed that there is no difference between the solution times for the three groups, it would be expected that the median times would be approximately equal for each group on every anagram. If the lowest of the three median times for each trial was recorded for all 15 anagrams, each group should have the fastest time on five of the anagrams. On examining our data, it was found that the $S$ group had the fastest median solution time on 10 of the 15 anagrams, the RS group on 1.5 of 15 , and the $\mathrm{R}$ group on 3.5 of 15 (giving .5 each for ties). This difference between the groups was significant $\left(X^{2}=7.90\right.$, df $\left.=2, p<.02\right)$.

In comparing the groups in pairs, it was found that the median solution times in the $S$ group were significantly faster than those in the RS group (MannWhitney $U$ test: $\left.U=63, n_{1}=n_{2}=15, p<.025\right)$. The differences in the other comparisons were not significant (RS vs $R$ : $U=97.5, n_{1}=n_{2}=15, p>.05$ and $R$ vs $S: U=88.5, n_{1}=n_{2}=15, p>.05$ ).

\section{Discussion}

The results supported the hypothesis that overtraining on a set method of anagram solution would facilitate the learning of a new mental set. This finding is in contrast with the results of Maltzman \& Morrisett (1952), but this discrepancy is probably due to a more prectse establishment of training (weak habit) and overtraining (strong habit) in the present study.

It is interesting to note that the $S$ group, even though receiving 45 training trials on a set method of solution, did not perform significantly better on the new set than did the $\mathbf{R}$ group, which had no previous set training. The implication here is that underlearning may be as conducive to the establishment of a mental set as overlearning is. The learning of a set without overtraining seems to impede the acceptance of a new set. Another study being planned will use larger groups and a contrived order of presentation of the anagrams to determine if in fact a mental set may be as easily adopted with no previous training as with overtraining on a different set.

\section{References}

MALTZMAN, I., \& MORRISETT, L. Different strengths of set in the solution of anagrams. J. exp. Psychol., 1952, 44, 242-246.

MALTZMAN, I., \& MORRISETT, L. The effects of single and compound classes of anagrams on set solutions. J. exp. Psychol., 1953, 45, 345-350.

REES, H. J., \& ISRAEL, H. E. An investigation of the establishment and operation of mental sets. Psychol Monogr., 1935, 46, No. 6 (Whole No. 210).

THORNDIKE, E. L., \& LORGE, I. The teacher's word book of 30,000 words. New York: Columbia University, Bureau of Publications, 1944. 